\title{
Correction to: Presenting symptoms in inflammatory bowel disease: descriptive analysis of a community-based inception cohort
}

Bryce K. Perler ${ }^{{ }^{*}}$ (D), Ryan Ungaro ${ }^{2}$, Grayson Baird ${ }^{3}$, Meaghan Mallette ${ }^{4}$, Renee Bright ${ }^{4}$, Samir Shah ${ }^{4}$, Jason Shapiro ${ }^{5}$ and Bruce E. Sands ${ }^{2}$

\section{Correction to: BMCGastroenterology (2019) 19:47} https://doi.org/10.1186/s12876-019-0963-7

Following publication of the original article [1], the authors identified an error in one of the authors' names. The correct author name should be Bryce K. Perler.

\section{Author details}

1 Department of Medicine, Warren Alpert Medical School of Brown University, Providence, USA. ${ }^{2}$ Dr. Henry D. Janowitz Division of Gastroenterology, Icahn School of Medicine At Mount Sinai, New York, USA. ${ }^{3}$ Lifespan Biostatistics Core, Rhode Island Hospital, Providence, USA. ${ }^{4}$ Department of Gastroenterology, Warren Alpert Medical School of Brown University, Providence, USA.

${ }^{5}$ Department of Pediatric Gastroenterology, Warren Alpert Medical School of Brown University, Providence, USA.

Published online: 03 December 2020

\section{Reference}

1. Perler, et al. Presenting symptoms in inflammatory bowel disease: descriptive analysis of a community-based inception cohort. BMC Gastroenterol. 2019;19:47. https://doi.org/10.1186/s12876-019-0963-7.

\section{Publisher's Note}

Springer Nature remains neutral with regard to jurisdictional claims in published maps and institutional affiliations. 